\title{
Continuum of Surgical Skill Acquisition for the Postgraduate Residents During COVID Pandemic: Role of Advanced Simulators in a Multipronged Modular Approach
}

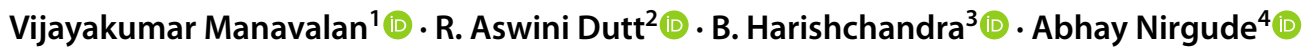

Received: 19 July 2021 / Accepted: 29 October 2021 / Published online: 9 November 2021

(C) Indian Association of Surgical Oncology 2021

\begin{abstract}
Skill acquisition with required competencies as defined by the National Medical Commission for the postgraduate surgical residents can happen in a step-wise manner from novice or advanced beginner to competent levels. This requires well-defined program-specific objectives, teaching-learning and assessment methods as per the competency-based medical education curriculum. Various modalities of teaching for the residents are adapted during the COVID pandemic to maintain the continuum of learning. In this study, we have attempted to develop, implement, and evaluate the effectiveness of acquiring laparoscopic surgical skills using advanced simulators and with large live animal in a real-life situation by a modular training approach. This skill-based program was developed and implemented for final year General Surgery postgraduate residents of Yenepoya Medical College for training laparoscopic surgical competencies. The training was conducted at Advanced Simulation Centres of Yenepoya (Deemed to be University), Mangalore, Karnataka, India. Three training modules were prepared based on the competency-based medical education curriculum for incremental training with advanced simulators and large live animals in a real-life situation which included the sessions on briefing, scenarios, simulations, hands-on activities, debriefing, feedback, and assessment methods. Assessment after the modular training showed statistically significant improvement in their scores, and they scaled up their skill acquisition ladder after each module. The residents and faculty felt that integration from different specialties has increased their confidence levels and communication skills, exploring team dynamics with 1:1 mentorship to make them competent emphasizing the effectiveness of simulation-based training even during the pandemic.
\end{abstract}

Keywords Competency $\cdot$ Laparoscopy $\cdot$ Module $\cdot$ Skill $\cdot$ Simulation

\section{Background}

Skill acquisition is an essential component for surgical residents' training during their post-graduation studies. They move across the ladder step by step from novice/advanced

Vijayakumar Manavalan

vicechancellor@yenepoya.edu.in

R. Aswini Dutt

drdut23@yahoo.com

B. Harishchandra

bharishchandra@rediffmail.com

Abhay Nirgude

abhaynirgude@gmail.com

1 Department of Surgical Oncology, Yenepoya Medical College, Yenepoya (Deemed to be University), Mangalore, Karnataka, India beginner to competent to proficient levels. Being at the postgraduate level, the residents need to demonstrate the "Shows How" and "Does" competencies as per the Miller's pyramid of clinical competence [1].

Department of Physiology, Yenepoya Medical College, Yenepoya (Deemed to be University), Mangalore, Karnataka, India

3 Department of General Surgery, Yenepoya Medical College, Yenepoya (Deemed to be University), Mangalore, Karnataka, India

4 Department of Community Medicine, Yenepoya Medical College, Deputy Director, Yenepoya Centre for Faculty Development, Yenepoya (Deemed to be University), Mangalore, Karnataka, India 
The Medical Council of India in 2017 has rolled out a competency-based postgraduate curriculum across all the programs. Accordingly, 15 program outcomes/Subject Specific learning objectives and program-specific outcomes/ subject-specific competencies in all 3 domains of learning; knowledge (cognitive domain), professionalism (affective domain), and skills (psychomotor domain) have been defined in the postgraduate training program for MS in General surgery [2]. This curricular framework stresses the importance of specialist postgraduate training in recent advances addressing the health needs of the community and competent enough to handle effectively medical/surgical problems with empathy and humane approach [3]. The advancement of information technology has largely assisted the training programs.

Simulation-based skill training is a newer modality which has various advantages for the trainees to enhance their clinical skills in real life like situation which is ethical and stress-free and occurs in a safe environment $[4,5]$. High fidelity simulators, virtual reality task trainers, animal models, and simulated patients form the components of simulation-based training programs $[6,7]$. This teaching and training strategy has been effectively adapted in the departments of anesthesia, emergency medicine, intensive care medicine, surgery, obstetrics, pediatrics, ophthalmology, and radiology in many institutions [8].

Skill training using simulation has been widely recognized, accepted, and implemented into the curriculum by various boards and committees across the globe $[9,10]$. With the newer developments in all the areas of medicine including surgical specialties, one of the most common skills that are essential to be acquired by a surgical resident at the end of their training is the basic laparoscopic skill. According to the American Board of Surgery, individuals are required to complete successfully an educational program entitled "The Fundamentals of Laparoscopic Surgery" (FLS) developed by the Society of American Gastrointestinal and Endoscopic Surgeons (SAGES), to be board certified in general surgery $[11,12]$.

COVID-19 pandemic has affected the teaching and training process of residents all programs and skill acquisition for them was a challenging task that was severely compromised and has come to a grinding halt due to the paucity of non-COVID cases admitting to the hospitals $[13,14]$. For maintaining the continuum of the learning process, different modalities were adapted by the institutions like virtual case-based discussions, seminar presentations, video-based surgical skills interactive training, online learning modules, virtual rounding, reflection assignments, surgical skills simulation training, research education, and medical education learning and journal clubs in virtual mode [15].

Simulation-based training for the residents in few centers with advanced surgical skill infrastructure has led to active learning amidst challenging situations. There are no well-structured and validated training modules in this latest technology-assisted skill acquisition training program. Under these circumstances, we, at the Department of General Surgery of Yenepoya Medical College, under the Yenepoya (Deemed to be University) aimed to develop, implement, and evaluate a modular training program with an assessment blueprint on laparoscopic surgical skills for the final year MS General Surgery postgraduate residents at the skill training centers of the University.

\section{Materials and Methods}

This module was developed and implemented for final year MS General Surgery postgraduate residents $(n=10)$ of Yenepoya Medical College of one cohort for training laparoscopic surgical skills. The simulation training was conducted at Advanced Surgical Skill Enhancement Division (ASSEND) and Advanced Comprehensive Clinical Training and Simulation Centre (ACTSYEN), Yenepoya (Deemed to be University), Mangalore, Karnataka, India, during October 2020 to March 2021. The animal ethics committee approval was obtained for the study (V-11011(13)/15/2020-CPCSIA-DADF dated $9^{\text {th }}$ October 2020).

ACTSYEN is the largest state-of-the-art simulation facility in the country equipped with a wide range of high fidelity mannequins, basic task trainers, three-dimensional virtual dissection table-Anatomage, and virtual reality simulators.

ASSEND is furnished with advanced equipment for surgical training like basic endo-trainers, electro-surgical devices, minimally invasive laparoscopic instruments, robotic setups, surgical microscope unit and a variety of open surgical instruments, animal model surgical training facilities, anesthesia equipment and monitors along with a team of trainers, veterinary surgeons, and technicians.

\section{Development of Simulation-Based Skill Enhancement Module}

The teaching faculty from the departments of General Surgery, Gastroenterology, Anesthesiology, and medical education brainstormed in developing the contents of the module which had learning objectives for each simulation session aligned with learning outcomes. The faculty involved from the Department of General Surgery had undergone laparoscopic training with an experience of 4 to 20 years and a surgical Gastroenterologist with advanced laparoscopy training.

All the 10 final year surgery postgraduate students of the 2018 batch were included in the training. The training modules were prepared following the guidelines for the competency-based medical education for raining in General Surgery after studying the basic training programs of professional bodies involved in the laparoscopy training with modifications as per the requirements of the trainees and available resources. A plan for the briefing, scenarios, 
Fig. 1 Modular training process with simulation

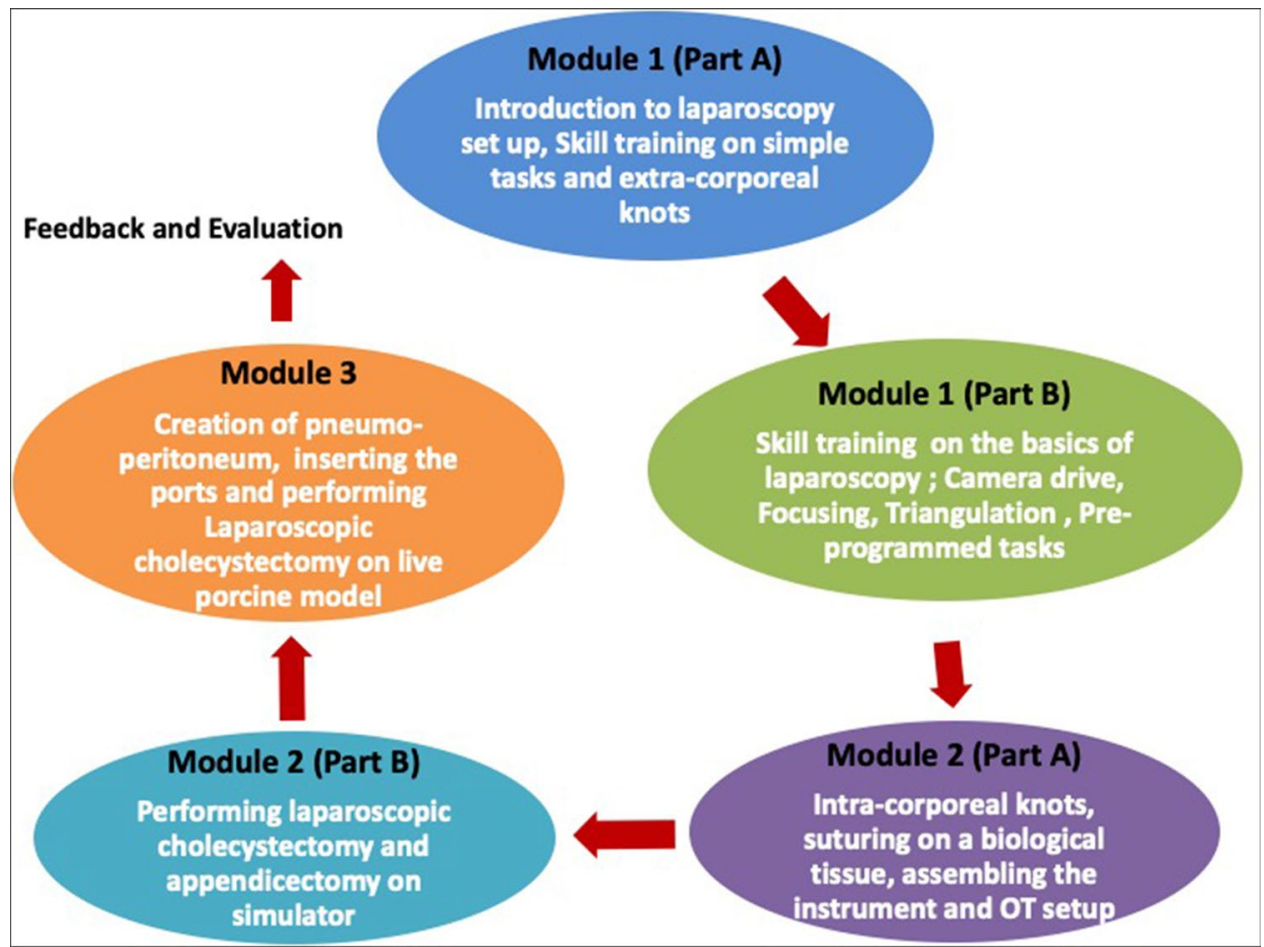

simulations, teaching-learning methods, debriefing, and evaluation methods was discussed and developed for each module for the implementation (Fig. 1).

\section{Module 1}

The objectives of this module were to make the residents understand the basic principles of laparoscopic surgery including the history, indications, types of equipment used and their assembly, operation theater (OT) setup, sterilization methods, and complications of laparoscopy. Also to train them to perform the simple tasks of hand to eye cordination, camcera driving, focusing and extracorporeal knotting.

The competencies of module 1, teaching-learning methods used with duration, assessment, and levels of learning are depicted in Table 1.

\section{Module 2}

The specific learning objectives of this module were to make the resident perform the simple laparoscopic steps such as setting up the equipment at OT for laparoscopic surgery, intra-corporeal knotting, and suturing on a biological tissue (chicken piece) and understand the individual steps, and perform diagnostic laparoscopy, laparoscopic cholecystectomy, and appendicectomy on a simulator.

The modular contents included are depicted in Table 2.

The residents were asked to practice all the tasks learned during the training workshop modules I and II for at least $10 \mathrm{~h}$ each. The assessment was conducted about 15 days after module II by the mentors on the knowledge of laparoscopic surgery and acquisition of sample tasks learnt. Viva and DOPS were used with a checklist for grading their performances. The laparoscopic tasks using endotrainer like building block exercise, putting the ring to the nail, putting a knot, suturing with silicon sheet, and peeling the grape and outside the endotrainer, extracorporeal knotting skills were used for training and assessment. All the students were assessed by the same expert involved in the process. Of the 10 students, 2 who underperformed were given additional training at the end of the assessment session.

\section{Module 3}

The specific learning objectives are to make the resident create pneumo-peritoneum and insert primary and secondary ports safely, perform diagnostic laparoscopy, and perform all the steps of cholecystectomy correctly and safely with hands-on training on live anesthetized animal (porcine). The contents are shown in Table 3.

During module III which was held once a month, 2 trainees were trained per session and they were assisted by 2 other trainees who would be operating during the next session in the following month. Two animals per session were used; each session included two students and two mentors. Accordingly, each resident performed a full cholecystectomy (skin to skin) on a porcine model.

One to one mentor trainee ratio was maintained, with the mentor guiding the trainee throughout the procedure to make 
Table 1 Contents of module 1

\begin{tabular}{|c|c|c|c|c|}
\hline S. No. & Competency area & Teaching learning method/duration & Assessment method & $\begin{array}{l}\text { Level of } \\
\text { learning } \\
\text { (Miller's) }\end{array}$ \\
\hline 1 & $\begin{array}{l}\text { - Introduction to laparoscopy (history, } \\
\text { evolution, applications), } \\
\text { - Ports, hand instruments and other equip- } \\
\text { ment, their assembly } \\
\text { - Sterilization techniques } \\
\text { - Energy devices } \\
\text { - Anesthesia in laparoscopic surgery, impli- } \\
\text { cations, modifications and complications } \\
\text { - Creation of pneumoperitoneum, knotting } \\
\text { techniques, } \\
\text { - Diagnostic laparoscopy, appendicectomy } \\
\text { and cholecystectomy at ACTSYEN using } \\
\text { laparoscopic virtual reality simulator } \\
\text { (CAE Co.) }\end{array}$ & $\begin{array}{l}\text { Short lectures with demonstrations, illustra- } \\
\text { tions, photographs and video clippings } \\
(4 \mathrm{~h})\end{array}$ & Pre-test and post-test & Knows how \\
\hline 2 & $\begin{array}{l}\text { - Skill training on simple tasks } \\
\text { - Extra-corporeal knots at ASSEND }\end{array}$ & $\begin{array}{l}\text { Small group, DOAP- on the endotrainer } \\
\text { ( } 40 \text { min for each candidate) }\end{array}$ & $\begin{array}{l}\text { Viva and Direct Observa- } \\
\text { tion of Procedural Skills }\end{array}$ & Shows \\
\hline 3 & $\begin{array}{l}\text { Skill training on the basics of laparoscopy } \\
\text { such as } \\
\text { - Camera drive, } \\
\text { - Focusing, } \\
\text { - Triangulation } \\
\text { - Performing the pre-programmed tasks at } \\
\text { ACTSYEN using laparoscopic virtual real- } \\
\text { ity simulator (CAE Co.) }\end{array}$ & $\begin{array}{l}\text { Small group, DOAP- on laparoscopic } \\
\text { simulator } \\
\text { (40 min for each candidate) }\end{array}$ & (DOPS) & Shows \\
\hline
\end{tabular}

Table 2 Contents of module 2

\begin{tabular}{|c|c|c|c|c|}
\hline S. No. & Competencies & Teaching learning method/duration & Assessment method & $\begin{array}{l}\text { Level of } \\
\text { learning } \\
\text { (Miller's) }\end{array}$ \\
\hline 1 & $\begin{array}{l}\text { Intra-corporeal knots, suturing on a bio- } \\
\text { logical tissue (chicken piece), assembling } \\
\text { the instrument and OT setup at ASSEND } \\
\text { on endo-trainer }\end{array}$ & $\begin{array}{l}\text { Small group, DOAP* } \\
\text { (40 min for each candidate) }\end{array}$ & Viva and (DOPS)** using the checklist & Shows How \\
\hline 2 & $\begin{array}{l}\text { Performing diagnostic laparoscopy, laparo- } \\
\text { scopic cholecystectomy and appendicec- } \\
\text { tomy at ACTSYEN using laparoscopic } \\
\text { virtual reality simulator (CAE Co.) }\end{array}$ & $\begin{array}{l}\text { Small group, DOAP } \\
\text { (40 min for each candidate) }\end{array}$ & & Shows How \\
\hline
\end{tabular}

*DOAP Demonstration-Observation-Assistance-Performance

**DOPS Direct Observation of Procedural Skills

sure that the procedure is done the same as it is done in human beings to give a real-life experience for the trainees from the start to finish of the surgery. The dignity of life of the animal was maintained throughout the training session. All the animals who underwent laparoscopic cholecystectomy recovered well from anesthesia without any mortality related to the training program.

\section{Debriefing, feedback, and evaluation}

After the residents completed the entire module, they were administered a questionnaire regarding their skill acquisition and learning experience with simulations and feedback was sought at each station. A retro-pre questionnaire, based on the Dreyfus model of skill acquisition, was administered. The feedback from faculty involved in the planning and implementation of this skill training module was also collected. Assessment using a validated checklist (Table 4) to assess the outcome of the training on endotrainer was conducted 2 months after the completion of basic skill training about the identification and knowledge about the use of laparoscopic instruments, extracorporeal knotting, performing simple laparoscopic tasks on endotrainer, intra-corporeal knotting and suturing. The checklist includes the questions 
Table 3 Contents of module 3

\begin{tabular}{lllll}
\hline S. No. Competencies & $\begin{array}{l}\text { Teaching learning method/dura- } \\
\text { tion }\end{array}$ & Assessment method & Level of learning (Miller's) \\
\hline 1 & $\begin{array}{l}\text { Creation of pneumo-peritoneum, } \\
\text { inserting the ports, and perform- } \\
\text { ing all the steps of laparoscopic } \\
\text { cholecystectomy }\end{array}$ & $\begin{array}{c}1: 1 \text { Hands-on training on live } \\
\text { anesthetized animal (porcine) }\end{array}$ & Viva and DOPS with the checklist & Show How \\
& 2 h for each candidate) & \\
\hline
\end{tabular}

related to higher order cognitive and psychomotor skills. More weightage (80\%) was given to psychomotor component. The feedback from the residents and faculty along with assessment scores was analyzed. The assessment scores (preand post-test) were analyzed statistically using the paired $t$-test, with a $p$-value $<0.05$ taken as statistically significant (Statistical software IBM SPSS Version 23). MS Excel was used for data entry and generation of graphs. Google forms were used for assessment and feedback. Consensual validation of the whole module was done by 6 subject experts. There was $100 \%$ agreement among the experts.

\section{Results}

The residents perceived that the simulation-based modular training 1:1 mentorship during training facilitated skill-building, and enhanced their hand-eye coordination skills; the scenario resembled a real-life situation enabling their integrated and incremental skill acquisition with confidence (Fig. 2).

Students also felt that the process followed benefitted them and believe that advanced simulation-based skill training improves quality care and communication skills and become competent even during the COVID pandemic (Table 5).

The students were asked to grade their perception before and after their training using a retro-pre questionnaire on a scale of 1 to 5 where 1 is the lowest and 5 the highest score. The mean scores were calculated which showed statistically significant results with incremental skill acquisition (paired $t$-test) as shown in Table 6. The assessment grades of residents following the overall modular skill training showed
$40 \%$ of the residents achieving grade A and $60 \%$ grade B (Table 7).

Paired $t$-test

Faculty feedback on this simulation-based training revealed that this module benefits the residents in acquiring the relevant laparoscopic surgical skills (Table 8).

\section{Discussion}

In this study, we developed and evaluated the effectiveness of a simulation-based skill enhancement module for postgraduate surgical residents. Residents found that our modular skill-based training with 1:1 mentoring enhanced their competencies in a stepwise manner. According to Singh AG, simulation-based skill acquisitions are useful to teach a novice the basic psychomotor skills under the supervision with instant feedback which needs to be incorporated into the curriculum of the postgraduate program [16].

Any new psychomotor skill acquisition is based on the theory proposed by Fitts and Posner who have defined the step-by-step approach involved in this learning process. The first step is knowledge-based where the students gain the information on the background, basics involved, use of appropriate instruments for hand-eye coordination, precision, depth perception, dexterity, and spatial orientation which will be haphazard or not uniform. The next phase includes the application of cognitive components for perfomance-based training to know the synchronicity of movements. The trainee gains proficiency and smoothness in handling the setup with confidence for a given situation in the last phase $[17,18]$. This is in line with the process followed in our modular training program.

Table 4 Checklist for the post-training assessment of laparoscopic skills for MS General Surgery residents

\begin{tabular}{lll}
\hline S. No. & Skill assessed & Score (1-5) \\
\hline 1. & Ability to identify and describe the use of basic laparoscopic instruments (Knows how) & 1. Poor \\
2. & Ability to perform simple tasks of hand-eye coordination on endotrainer (Shows how) & $\mathbf{2 .}$ Fair \\
3. & Ability to make an extra-corporeal knot (Shows how) & $\mathbf{3 . ~ G o o d ~}$ \\
4. & Ability to perform intracorporeal knot on the endotrainer (Shows how) & $\mathbf{4 . ~ V e r y ~ G o o d ~}$ \\
5. & Perform intracorporeal suturing (Shows how) & $\mathbf{5 . \text { Excellent }}$ \\
\hline
\end{tabular}

Grading: A, above 21; B, 11 to 20; C, below 10 


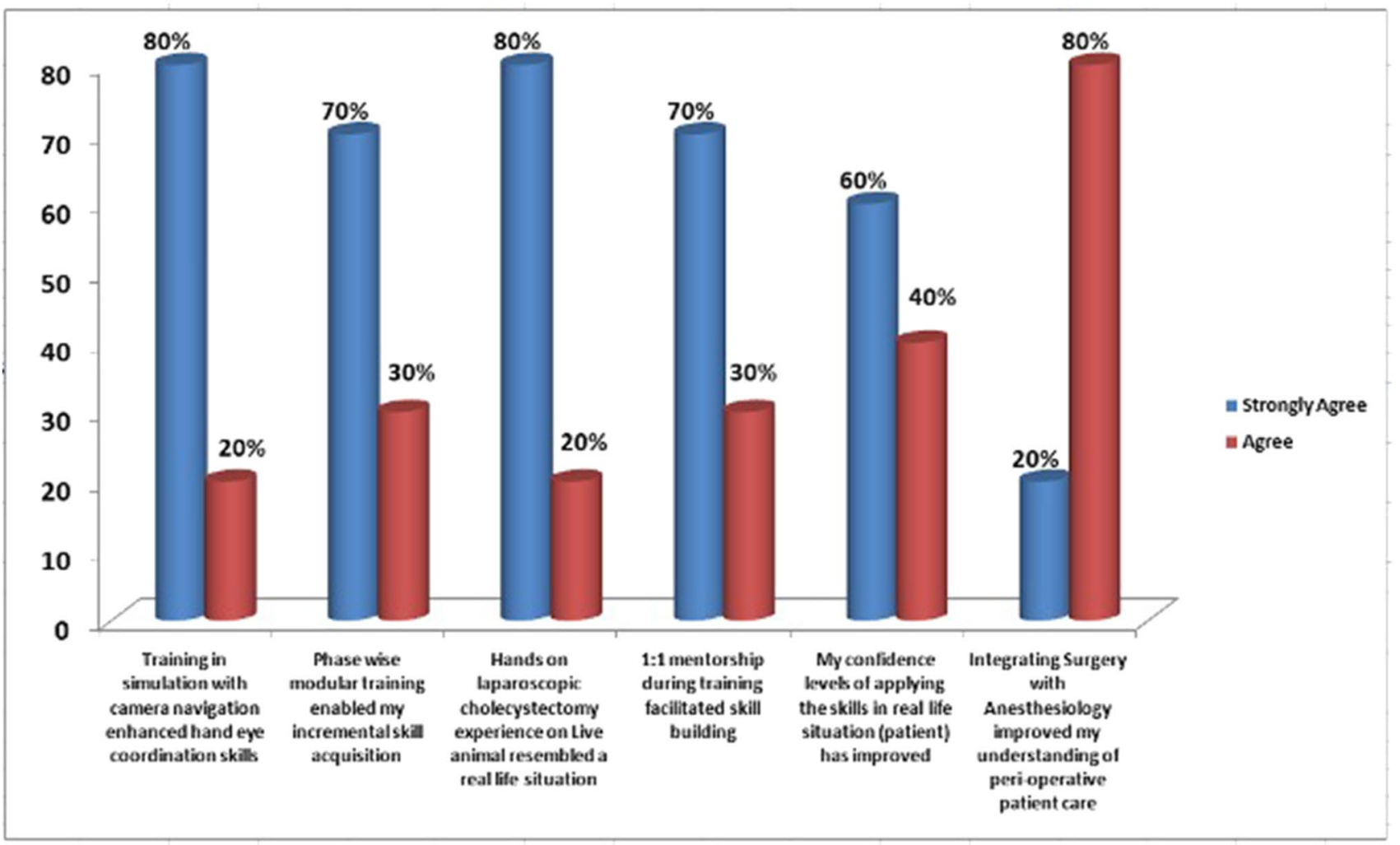

Fig. 2 Students' perception of simulation-based learning $(n=10)$

Table 5 Student perception on simulation-based training $(n=10)$

\begin{tabular}{|c|c|c|c|}
\hline Question & Strongly agree (\%) & Agree $(\%)$ & Neutral (\%) \\
\hline $\begin{array}{l}\text { Initial briefing helped me to understand the history, evolution, application, present status, and } \\
\text { future perspectives of simulation-based learning. }\end{array}$ & $5(50 \%)$ & $5(50 \%)$ & - \\
\hline $\begin{array}{l}\text { The debriefing session helped me in analyzing the challenges faced with probable solutions to } \\
\text { overcome them. }\end{array}$ & $6(60 \%)$ & $4(40 \%)$ & - \\
\hline Simulation training can improve patient safety and quality of healthcare. & $6(60 \%)$ & $2(20 \%)$ & $2(20 \%)$ \\
\hline ASSEND provides a safe non-threatening learning environment during this COVID pandemic. & $7(70 \%)$ & $2(20 \%)$ & $1(10 \%)$ \\
\hline $\begin{array}{l}\text { Sophisticated equipment, infrastructure facilities, and technology provided at ASSEND assisted } \\
\text { me in acquiring the clinical skills. }\end{array}$ & $6(60 \%)$ & $4(40 \%)$ & - \\
\hline Simulation can improve effective participation and communication skills & $7(70 \%)$ & $3(30 \%)$ & - \\
\hline Simulation in health care has advantages for training and gaining the competencies for residents & $6(60 \%)$ & $4(40)$ & - \\
\hline I would like to have more simulation-based training sessions. & $9(90 \%)$ & $1(10 \%)$ & - \\
\hline
\end{tabular}

Table 6 Pre-test and post-test scores of skill assessment after module $1(n=10)$

\begin{tabular}{llll}
\hline & Pre-test score & Post-test score & \\
\hline Mean & 4.80 & 8.20 & $P<0.0001$ \\
Standard & 1.14 & 1.48 & \\
deviation & & & \\
\hline
\end{tabular}

Simulation-based virtual reality training has greater advantages in reducing the errors and operating time with more accuracy, providing quality health care according to the 23 randomized control trials from the Cochrane library with 622 participants according to a study conducted by Gurusamy et al. which is in accordance with the observations in our study [19]. 
Table 7 Assessment grades of residents following the modular skill training $(n=10)$

\begin{tabular}{lll}
\hline Post-training assessment grade of laparoscopic skills & No of residents \\
\hline Grade A (Above 21) & $4(40 \%)$ \\
Grade B (11-20) & $6(60 \%)$ \\
Student perception of skill acquisition in each module & \\
Novice (Stage 1) to advanced beginner (Stage 2) & & $4(40 \%)$ \\
Novice (Stage 1) to competent (Stage 3) & & $1(10 \%)$ \\
Advanced beginner (Stage 2) to Competent (Stage 3) & Perceived skill levels before & Perceived skill levels after \\
Advanced beginner (Stage 2) to Proficient (Stage 4) & modular training & modular training \\
& 1.50 & 2.70 \\
Standard deviation & 0.53 & 0.67 \\
Standard error of the mean & & $1(10 \%)$
\end{tabular}

*Paired $t$-test

Table 8 Faculty feedback on simulation-based modular skill training $(n=7)$

\begin{tabular}{|c|c|c|c|}
\hline Question & Strongly agree $(\%)$ & Agree $(\%)$ & Neutral (\%) \\
\hline $\begin{array}{l}\text { Initial briefing helped the trainee to understand the history, evolution, application, present status, } \\
\text { and future perspectives of simulation-based learning. }\end{array}$ & $4(57 \%)$ & $3(43 \%)$ & - \\
\hline Training in simulation with camera navigation enhanced the trainee's hand-eye coordination skills. & $5(71 \%)$ & $2(29 \%)$ & - \\
\hline Hands-on laparoscopic cholecystectomy experience on live animals resembled a real-life situation. & $2(29 \%)$ & $5(71 \%)$ & - \\
\hline 1:1 mentorship during training facilitated skill-building. & $6(87 \%)$ & $1(13 \%)$ & - \\
\hline Phase-wise modular training enabled incremental skill acquisition by the trainees. & $5(71 \%)$ & $2(29 \%)$ & - \\
\hline $\begin{array}{l}\text { The trainee's confidence levels of applying the skills in a real-life situation (patient) have } \\
\text { improved. }\end{array}$ & $2(29 \%)$ & $4(57 \%)$ & $1(14 \%)$ \\
\hline $\begin{array}{l}\text { Integrating surgery with anesthesiology improved the trainee's understanding of perioperative } \\
\text { patient care. }\end{array}$ & $2(29 \%)$ & $4(57 \%)$ & $1(14 \%)$ \\
\hline $\begin{array}{l}\text { The debriefing session helped the trainees in analyzing the challenges faced with probable solu- } \\
\text { tions to overcome them. }\end{array}$ & $3(43 \%)$ & $4(57 \%)$ & - \\
\hline Simulation training can improve patient safety and quality of healthcare. & $4(57 \%)$ & $2(29 \%)$ & $1(14 \%)$ \\
\hline ASSEND provides a safe non-threatening learning environment during this COVID pandemic. & $4(57 \%)$ & $3(43 \%)$ & - \\
\hline $\begin{array}{l}\text { Sophisticated equipment, infrastructure facilities, and technology provided at ASSEND helped the } \\
\text { trainees in acquiring the skill. }\end{array}$ & $3(43 \%)$ & $4(57 \%)$ & - \\
\hline Simulation can improve effective participation and communication skills. & $4(57 \%)$ & $2(29 \%)$ & $1(14 \%)$ \\
\hline Simulation in health care has advantages for training and gaining the competencies for residents. & $4(57 \%)$ & $3(43 \%)$ & - \\
\hline Overall this module is beneficial to the residents. & $6(86 \%)$ & $1(14 \%)$ & - \\
\hline An effective skill training happens with such a simulation module. & $4(57 \%)$ & $3(43 \%)$ & - \\
\hline $\begin{array}{l}\text { The level of laparoscopic skills and confidence in performing the laparoscopic tasks by the train- } \\
\text { ees has improved after the basic laparoscopic skill training. }\end{array}$ & $3(43 \%)$ & $3(43 \%)$ & $1(14 \%)$ \\
\hline $\begin{array}{l}\text { Development and implementation of such simulation module requires a collaborative approach } \\
\text { with other departments. }\end{array}$ & $3(43 \%)$ & $4(57 \%)$ & - \\
\hline The development and implementation of such a simulation module is time-consuming. & $3(43 \%)$ & $3(43 \%)$ & $1(14 \%)$ \\
\hline I would like to be a faculty during future simulation-based training sessions. & $2(29 \%)$ & $5(71 \%)$ & - \\
\hline
\end{tabular}

Seymour et al. in 2002 demonstrated the transfer of virtual reality training skills to the operating room environment involving 16 surgical residents in a prospective, randomized, blinded study where they found that virtual reality surgical simulation training to reach specific target criteria significantly improved the performance of residents in an operating room in laparoscopic cholecystectomy [20].

We found that assessment of residents after this modular training showed statistically significant improvement in skill acquisition, team dynamics, and time management in a stress-free environment which follows the previous 
studies that reemphasized the role of simulation in improving the learning process [21-23].

A 5-day workshop of 50 residents of 5 sessions with 10 residents in each small group conducted at All India Institute of Medical Sciences, New Delhi, in medical, surgical, trauma, and mixed cases scenarios showed that their confidence levels increased from 48 to $76 \%$, communication aspects from $38 \%$ to $76 \%$, the tendency to blame team members decreased from $58 \%$ to $36 \%$, enhanced hand-eye coordination skills, $86 \%$ were ready to participate as a team, and effective learning outcome was achieved [24].

Some of the limitations of the modular training are:

- Anatomy of the model (porcine) though similar is different from that of the human beings. There are multiple lobes of liver in a porcine animal as compared to human beings (difficult), cystic duct is thin and elongated (easy), and cystic artery is very fine (easy). Hence, the training need not reflect the real life situation as there can be several anatomical variations in humans developmentally or due to disease or previous surgery.

- The skill training on the animal model was mainly on the basics of laparoscopy and laparoscopic cholecystectomy, but the other common procedural skills could not be imparted due to lack of appropriate models.

In this study, the training was conducted for the final year residents. Training the second year students could be considered the future scope as the students will continue their resident surgical training program for a longer period after their basic laparoscopic skill training and would be involved with surgeries on actual patients under supervision of the mentors. We feel that the skill training of the surgical residents on a live anesthetized animal, following all the steps and care exactly as an actual patient, gives a real-life experience as compared to training on a cadaver as it provides the experience of operating on a live tissue to the trainee.

Success of this modular program enabled us to conduct similar training for surgical oncology trainees in GI oncology and uro-oncology procedures. Here the focus was on advanced surgical skills as the trainees are qualified general surgeons having required surgical skills. They performed rectal mobilization, dissection of inferior mesenteric vessels, hysterectomy, omentectomy, wedge resection of liver, peritoneal biopsy, partial nephrectomy, and radical nephrectomy, on live porcine models.

\section{References}

1. Miller GE (1990) The assessment of clinical skills/competence/ performance. Acad Med 65:63-67
2. Postgraduate MS Surgery Curriculum. National Medical Commission. https://www.nmc.org.in/wp-content/uploads/2019/09/ MS-Surgery.pdf (Accessed on 16.7.2021)

3. Harden RM (2006) Trends and the future of postgraduate medical education. Emerg Med J. 23(10):798-802

4. Sajid AW, Gordon MS, Mayer JW et al (1980) Symposium: a multi-institutional research study on the use of simulation for teaching and evaluating patient examination skills. Annual Conference Res Med Educ 19:349-358

5. Spiliotis AE, Spiliotis PM, Palios IM (2020) Transferability of simulation-based training in laparoscopic surgeries: a systematic review. Minim Invasive Surg 2(1):10. https://doi.org/10.1155/ 2020/5879485

6. Chan B, Martel G, Poulin EC, Mamazza J, Boushey RP (2010) Resident training in minimally invasive surgery: a survey of Canadian department and division chairs. Surg Endoscopy 24(3):499_ 503. https://doi.org/10.1007/s00464-009-0611-3

7. Palter VN, Orzech N, Aggarwal R, Okrainec A, Grantcharov TP (2010) Resident perceptions of advanced laparoscopic skills training. Surg Endoscopy 24(11):2830-2834

8. Ziv A, Ben-David S, Ziv M (2005) Simulation based medical education: an opportunity to learn from errors. Med Teach 27:193-199

9. Rooney DM, Santos BF, Hungness ES (2012) Fundamentals of laparoscopic surgery (FLS) manual skills assessment: surgeon vs nonsurgeon raters. J Surg Educ 69(5):588-592

10. Overby DW, Watson RA (2014) Hand motion patterns of fundamentals of laparoscopic surgery certified and noncertified surgeons. Am J Surg 207(2):226-230

11. Scott DJ, Cendan JC, Pugh CM, Minter RM, Dunnington GL, Kozar RA (2018) The changing face of surgical education: simulation as the new paradigm. J Surg Res 147(2):189-193

12. Scott DJ, Dunnington GL (2008) The new ACS/APDS Skills Curriculum: moving the learning curve out of the operating room. $\mathrm{J}$ Gastrointestinal Surg 12(2):213-221

13. Ellison EC, Spanknebel K, Stain SC et al (2020) Impact of the COVID-19 pandemic on surgical training and learner well-being: report of a survey of general surgery and other surgical specialty educators. J Am Coll Surg 231(6):613-626

14. Khan KS, Keay R, McLellan M, Mahmud S (2020) Impact of the COVID-19 pandemic on core surgical training. Scottish Med J 65(4):133-137

15. Tuma F, Kamel MK, Shebrain S, Ghanem M, Blebea J (2021) Alternatives surgical training approaches during COVID-19 pandemic. Ann Med Surg (Lond). 62:253-257

16. Singh AG (2018) Simulation-based training in laparoscopic urology - pros and cons. Indian J Urol 34(4):245-253. https://doi.org/ 10.4103/iju.IJU_213_18

17. Anastakis DJ, Regehr G, Reznick RK, Cusimano M, Murnaghan J, Brown M et al (1999) Assessment of technical skills transfer from the bench training model to the human model. Am J Surg 177:167-170

18. Rowan AN (1993) Is justification of animal research necessary? JAMA 269:1113-1114

19. Gurusamy K, Aggarwal R, Palanivelu L, Davidson BR (2008) Systematic review of randomized controlled trials on the effectiveness of virtual reality training for laparoscopic surgery. Br J Surg 95(9): 1088-1097

20. Seymour NE, Gallagher AG, Roman SA et al (2002) Virtual reality training improves operating room performance. Annals Surg 236(4):458-464

21. Shapiro MJ, Morey JC, Small SD, Langford V, Kaylor CJ, Jagminas L et al (2004) Simulation based teamwork training for emergency department staff: does it improve clinical team performance when added to an existing didactic teamwork curriculum? Qual Saf Health Care 13:417-421 
22. Gaba D, Howard SK, Fish K (2001) Simulation based training in anaesthesia crisis resource management: a decade of experience. Simulation Gaming 32:175-193

23. Grantcharov TP, Kristiansen VB, Bendix J, Bardram L, Rosenberg J, Funch-Jensen P (2004) Randomized clinical trial of virtual reality simulation for laparoscopic skills training. Br J Surg 91:146-150
24. Gupta A, Peckler B, Schoken D (2008) Introduction of hi-fidelity simulation techniques as an ideal teaching tool for upcoming emergency medicine and trauma residency programs in India. $\mathbf{J}$ Emerg Trauma Shock 1(1):15-18

Publisher's Note Springer Nature remains neutral with regard to jurisdictional claims in published maps and institutional affiliations. 